\title{
CHLOROPHYLL FLUORESCENCE PHOTOGRAPHY TO DETECT MUTANTS, CHILLING INJURY AND HEAT STRESS
}

\author{
by \\ GREGORY C. GIBBONS \\ Department of Biotechnology, Carlsberg Research Laboratory, \\ Gamle Carlsberg Vej 10, DK-2500 Copenhagen Valby \\ and \\ ROBERT M. SMILLIE
}

Plant Physiology Unit, CSIRO Division of Food Research and School of Biological Sciences, Macquarie University, P.O. Box 52, North Ryde 2113, Sydney, Australia

and

Department of Physiology, Carlsberg Laboratory,

Gamle Carlsberg Vej 10, DK-2500 Copenhagen Valby

Keywords: Barley, papaya, tomato, potato, pea, chlorophyll fluorescence kinetics, chloroplast mutants, protochlorophyllide mutants, somatic hybrids

\begin{abstract}
Chlorophyll fluorescence photography with high speed colour film has been used to examine: (i) kinetics of the rise and fall of variable fluorescence in barley leaves, (ii) detection of high fluorescing mendelian and maternally inherited mutants of barley, (iii) detection of protochlorophyllide-deficient and protochlorophyllideaccumulating mutants of barley, (iv) heat stress by photographing the increase of initial fluorescence in heated leaves, and $(\mathrm{v})$ decrease in variable fluorescence in leaves of peanut, tomato and tomato-potato somatic hybrids associated with the development of chilling injury. Filter combinations and a light source for photographing chlorophyll fluorescence are described. The relative intensity and kinetics of the fluorescence from the plants photographed was also measured, so that this could be correlated with fluorescence as detected by photography, and to facilitate the determination of optimal conditions for fluorescence photography.
\end{abstract}

Abbreviations: $F_{\mathrm{o}}=$ initial fluorescence; $F_{\mathbf{v}}=$ variable fluorescence; $F_{\mathrm{s}}=$ steady state fluorescence. 


\section{INTRODUCTION}

When photosynthetic organisms absorb photons via chlorophyll, a portion of the acquired energy, usually less than one percent, is dissipated by emission as radiation. The intensity of this chlorophyll fluorescence is correlated with photosynthetic electron transfer activity and chlorophyll fluorescence is frequently employed as a means of studying photosynthetic mechanisms (for reviews see refs. 2, 10, 20).

Increasingly, in vivo chlorophyll fluorescence is also being used to assess the effects of genetic, environmental and other stresses on green plant cells. This follows from the fact that in vivo chlorophyll fluorescence makes available one of the very few methods for monitoring in intact cells the activity of a membrane system, the functional state of which is likely to alter as cells become stressed. Two areas in particular have benefitted from the development of practical measurements and screening procedures based on chlorophyll fluorescence. Firstly, the detection of photosynthetic mutants $(1,11,15,26$, 32) and secondly, monitoring the development of injury to plant cells resulting from an applied stress including chilling $(12,28)$, freezing (13, 19), high temperatures $(21,23,27,31)$, water (33) or oxygen (24) deficits, and ozone toxicity (25).

Chlorophyll fluorescence may be detected visually, photographically using colour $(3,16)$ or black and white film (4), or by using a lightmeasuring device. In some applications the first two methods may offer advantages over actual measurements of fluorescence, such as in the development of a rapid mass screening method. However, neither method has seen much use to date and this can largely be attributed to the fairly complex changes in the kinetics of the fluorescence rise following illumination. This makes it imperative to know the extent and time course of the fluorescence changes taking place before optimal conditions for observation and photography can be attained. We have attempted to do this by combining photography with actual measurements of the kinetics of chlorophyll fluorescence. By this means, conditions suitable for chlorophyll fluorescence photography were established and its use demonstrated for detecting high and low fluorescing nuclear gene mutants of barley, a high fluorescing maternally inherited mutant of barley, and for following the onset of injury caused by chilling or high temperatures.

\section{MATERIALS AND METHODS}

\subsection{Plant material}

Dark-grown leaves of Hordeum vulgare L. cv. Svalöfs Bonus, and the mutants xantha- $l^{81}$ and tigrina-d $d^{12}$ derived from Svalöfs Bonus were obtained from 7-day-old seedlings, grown in vermiculite at $21^{\circ} \mathrm{C}(70 \%$ r.h.). Light-grown leaves of Hordeum vulgare L. cv. Svalöfs Bonus and the Svalöf's Bonus derived mutants viridis$n^{34}$ and viridis $-e^{64}$, were obtained from 7-day-old seedlings, grown under continuous light $(3200$ lux) at $20^{\circ} \mathrm{C}$ in moist vermiculite. The maternally inherited mutant, Coast $\mathrm{V}$, and the wild type from which it was derived, Coast CI-690, were grown in the same way under continuous light. Carica papaya L. leaves were obtained from a plant grown under continuous light (1000 lux) at $20^{\circ} \mathrm{C}$. Two somatic hybrids of Solanum tuberosum L., dihaploid stock HH 258 and Lycopersicon esculentum Mill var. cerasiforme, mutant yellow green 6, RICK, were derived from the plants described by Melchers et al. (14) and Poulsen et al. (22). The hybrids were $7 \mathrm{c} / 13 / \mathrm{S} 25$ with 58 chromosomes and potato chloroplast DNA, and $2 \mathrm{a} / 2 \mathrm{a} / 36 \mathrm{~d} / \mathrm{S} 3$ with 49 (48) chromosomes and tomato chloroplast DNA (22). Parent and hybrid plants were grown in a green-house with a day temperature of $25 \pm 2^{\circ} \mathrm{C}$ and a night temperature of $20 \pm$ $2{ }^{\circ} \mathrm{C}$. Leaves of Pisum sativum L. were obtained from plants grown in a growth chamber with a 16 hour day at $28^{\circ} \mathrm{C}(6700$ lux $)$ and an 8 hour night at $24^{\circ} \mathrm{C}$.

\subsection{Chilling}

Leaves were detached at the base of the petiole and placed on moistened filter paper in a darkened Petri dish. The Petri dish was immersed in ice and stored in a cold room $\left(2-5^{\circ} \mathrm{C}\right)$ for 24 hours. Unchilled leaves were similarly stored in Petri dishes at $18{ }^{\circ} \mathrm{C}$ in darkness. Chilled and control leaves were photographed at $0^{\circ} \mathrm{C}$ by placing the leaves on an aluminium plate embedded in melting ice. 


\subsection{Heating}

Leaf pieces were placed under glass on a highly insulated $5 \times 3 \times 1 \mathrm{~cm}$ copper heating block. Water loss from the leaves was prevented by placing a small square of moistened lens tissue beneath the leaf segment and by taping the glass to the block. The block contained a series of $7 \mathrm{~mm}$ diameter channels and was connected with insulated rubber tubing to a Heto gradient heating bath type 02 PG 623 UL (Heto, Birkerød, Denmark). The heating rate was controlled at $1^{\circ} \mathrm{C}$ per min. When cooling was required, two cold finger units (Heto type CF3, Heto, Birkerød, Denmark) placed in the same UL bath as the gradient unit were used.

The temperature on the top of the leaves was monitored using a $0.1 \mathrm{~mm}$ stainless steel encapsuled nickel/chrome/nickel thermocouple (total diameter $1 \mathrm{~mm}$ ), connected to a CRL thermocouple unit type 204 equipped with a cold reference junction (Control and Readout Ltd., Worthing, England).

\subsection{Illumination of leaves}

Leaves were illuminated using a Reichert HBO 50 L2 super pressure mercury lamp unit (Reichert, Vienna, Austria) fitted with the appropriate filters. Illumination was carried out at an angle of $45^{\circ}$ to the focal plane of the camera at a distance of $50 \mathrm{~cm}$. The size of the lighted area was controlled by a quartz glass collector in the lamphouse.

\subsection{Filters}

Interference filters were manufactured by Optisk Laboratorium, Lyngby, Denmark. Red glass filters were obtained from Nikon, Tokyo, Japan, Schott, Mainz, West Germany and Zeiss, Jena, East Germany. Red gelatine filters were from Kodak, Rochester, N.Y., U.S.A.

\subsection{Photography}

All photographs were taken with a Nikon $F$ camera using a Micro Nikkor $55 \mathrm{~mm} \mathrm{f} 3.5$ objective and two Nikon PK 13 extension rings (Nikon, Tokyo, Japan). To facilitate focussing at low light levels, a Nikon F, type B, mat screen was used. All photography was carried out in a dark room to eliminate stray light. Colour reversal film of types Ektachrome 400 (daylight) and Ektachrome 160 (tungsten) were obtained from Kodak, Rochester, N.Y., U.S.A.

\subsection{Spectroscopy and fluorescence measure- ments}

Transmission spectra were recorded on a Shimadzu MPS 5000 spectrophotometer (Shimadzu, Kyoto, Japan). Fluorescence kinetic measurements were made using a Plant Productivity Fluorimeter, Model SF10 (Richard Brancker Research Ltd., Ottawa, Canada). Fluorescence spectra of filters were measured on a Jasco FP 550 spectrofluorimeter (Jasco, Tokyo, Japan) and room temperature and low temperature emission spectra of leaves measured on a fluorescence spectrometer with fibreglass optics from Applied Photophysics Ltd., London, England.

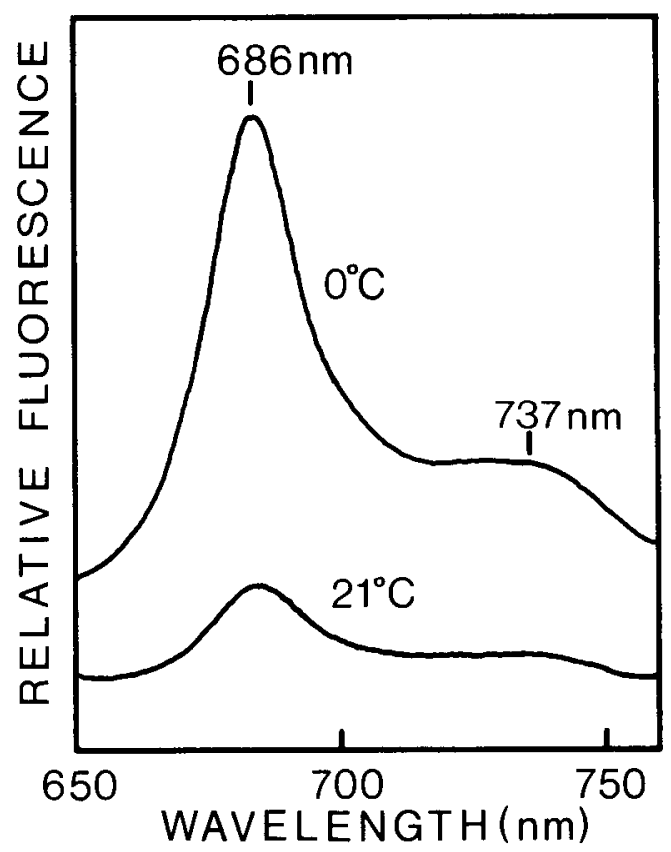

Figure 1. Fluorescence emission spectra of the primary leaf of barley at $21^{\circ} \mathrm{C}$ and at $0^{\circ} \mathrm{C}$.

The leaves were illuminated with white light filtered through a Corning 4-96 blue-green filter. The spectrum of the leaf at $21^{\circ} \mathrm{C}$ was recorded after 1 min of illumination and that of the leaf at $0^{\circ} \mathrm{C}$ without pre-illumination. 


\section{RESULTS AND DISCUSSION}

\subsection{Photography}

The blue-light induced red fluorescence of leaf chlorophyll is a well established phenomenon. Figure 1 shows the fluorescence emission spectra of a barley leaf at $21^{\circ} \mathrm{C}$ and at $0^{\circ} \mathrm{C}$. When the dark-adapted leaf is irradiated with blue light there is a transient rise in fluorescence during the first few seconds followed by a slower fall to a steady state level (see section 3.2). The fluorescence emission spectrum at $21^{\circ} \mathrm{C}$ is of this steady state fluorescence, since the transient rise is too short in duration to allow a spectrum to be run using a conventional spectrofluorimeter. There is a peak at $686 \mathrm{~nm}$ and a smaller peak at $737 \mathrm{~nm}$. The magnitude and life of the transient peak can be increased by inhibitors which block electron transfer on the reducing side of photosystem II (e.g. DCMU) or by temperature lowering. When the temperature of the dark-adapted barley leaf is lowered to $0^{\circ} \mathrm{C}$ prior to irradiation, the initial rise in fluorescence yield is maintained long enough for an emission spectrum to be recorded. The $686 \mathrm{~nm}$ peak is still much more prominent than the 738 $\mathrm{nm}$ peak at $0^{\circ} \mathrm{C}$, but the fluorescence yield at both wavelengths is considerably greater than at $21^{\circ} \mathrm{C}$. As will be discussed below, it may be desirable in some applications of chlorophyll fluorescence photography to record the maximum fluorescence rise on film, in others, photographing the steady state fluorescence may be preferable.

In order to record fluorescence events photographically, the blue exciting light must be of high intensity and not overlap the red end of the visible spectrum. Such excitation conditions are conveniently met by the use of a high pressure mercury arc light source equipped with high transmission focussing optics and combined with a short wave pass interference filter with effective red blocking. In the present work we chose a short wave pass SWP-485 nm interference exciter filter (Figure 2A) together with a 50 $\mathrm{W}$ high pressure mercury arc lamp (Figure $2 \mathrm{C}$ ) fitted with quartz collector optics.

On the emission side (i.e. prior to the light reaching the film) equally stringent blue blocking characteristics are required in order to remove all photographically recordable traces of the exciting beam. Such characteristics are apparently found in normal red-glass filters (e.g. Nikon $R$ 60, Schott RG 590, RG 600, Zeiss R271, Kodak Wratten 25). When, however, a blue-light excited leaf is viewed through such a red-glass filter, the image is seen to be blurred and the background reddish. This is due to autofluorescence in the red-glass. The transmission spectrum of such a red-glass filter is seen in Figure 2B together with a fluorescence spectrum of the same filter excited with blue light. The red autofluorescence of red-glass filters makes them unacceptable for chlorophyll fluorescence photography. To overcome this problem interference filters were used. Interference filters reflect the undesired wavelengths rather than absorbing them and are therefore not autofluorescent. The spectral characteristics of two well-suited filters are shown in Figure 2A. The long wave pass LWP-590 nm filter permits recording of both the $686 \mathrm{~nm}$ and $737 \mathrm{~nm}$ chlorophyll fluorescence peaks (Figure 1) when infrared sensitive film is used. When normal daylight colour film is used the low sensitivity of the red-sensitive cyan-dyes above $700 \mathrm{~nm}$ (Figure $2 \mathrm{C}$ ) results in a failure of the film to record the $737 \mathrm{~nm}$

Figure 2. Spectral characteristics.

A: Transmission spectra for the blue light excitation filter SWP-485 nm (-), the orange-red emission filter LWP-590 nm (-...--), the red band pass filter BP-600-700 nm (-- - ). B: Transmission and fluorescence spectra of a Nikon R 60 red glass filter. The transmission spectrum (-) was measured on a Shimadzu MPS-5000 spectrophotometer. The fluorescence spectrum (.......) was measured on a Jasco FP-550 spectrofluorometer using an excitation of $420 \mathrm{~nm}$ (slit $10 \mathrm{~nm}$ ) and scanning with an emission slit of $20 \mathrm{~nm}$. C: Relative spectral irradiance of a high pressure mercury arc lamp (-). The data are taken from the manufacturers specifications (Illumination Industries, Inc., Sunnyvale, California, USA). Spectral sensitivity of the red-absorbing cyan-forming layer of Kodak Ektachrome 400 film (daylight) (-- - ). The data are taken from the manufacturers specifications (Kodak, Rochester, N.Y., USA). Sensitivity is here defined as the reciprocal of exposure (ergs. $\mathrm{cm}^{-2}$ ) required to produce a specific film density of 1.0 . 
G. C. GibBons \& R. M. SmiLlie: Chlorophyll fluorescence photography

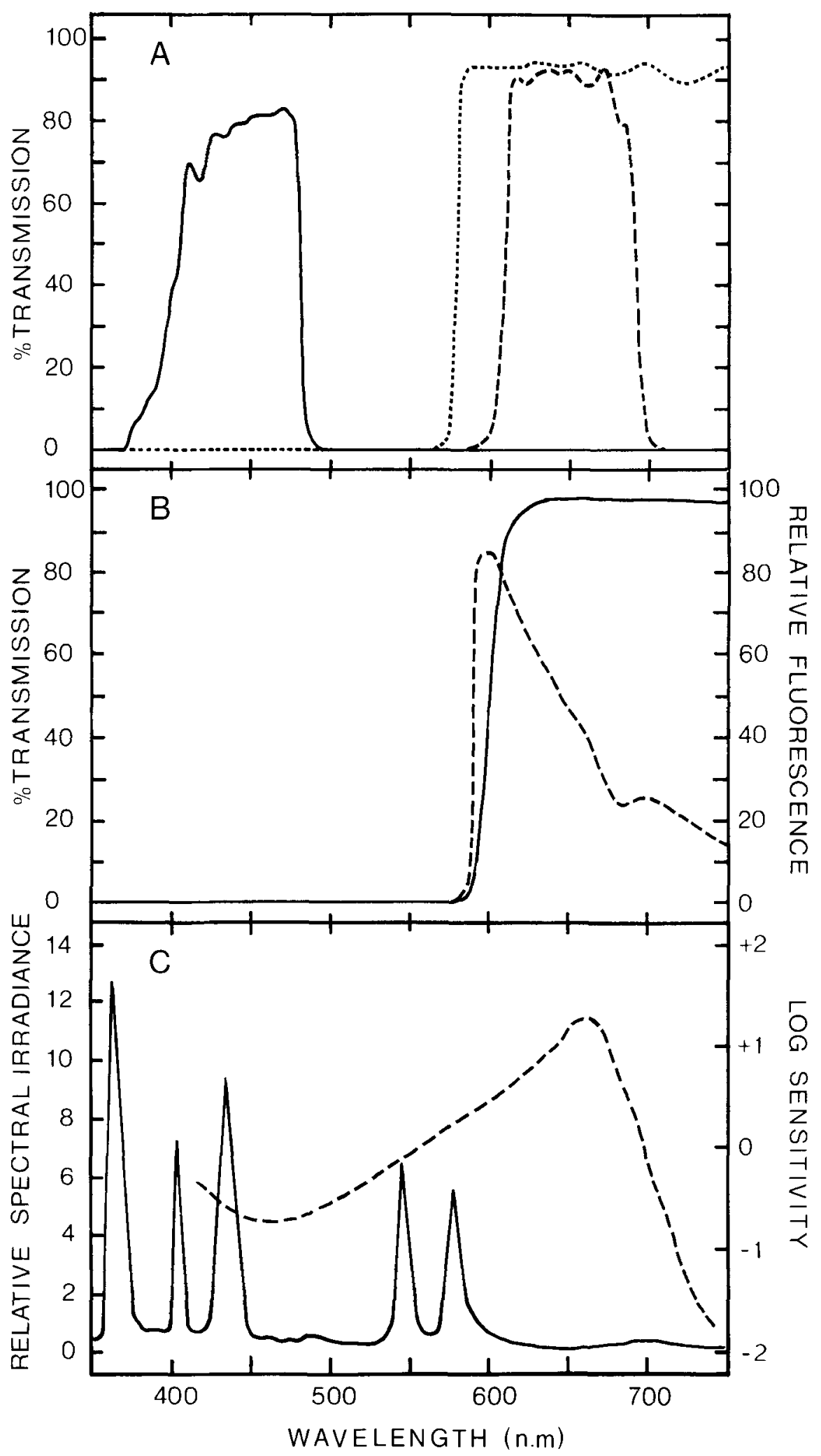


chlorophyll fluorescence peak. When selective measurement of the $686 \mathrm{~nm}$ chlorophyll peak is required, the band pass BP $600-700 \mathrm{~nm}$ interference filter can be employed (Figure 2A). Although exposures of longer than $0.1 \mathrm{sec}$ on daylight film in general induce reciprocity failure (the Schwarzschild effect) and colour balance shifts $(6,7)$, daylight film was found to give better results than artificial light balanced film even with long exposures (up to $80 \mathrm{sec}$ ). This is partly due to the greater relative red sensitivity of daylight balanced colour film compared with artificial light (tungsten) film (9).

\subsection{Kinetics}

In order to optimize the photographic conditions the kinetics of the processes involved in chlorophyll fluorescence must be considered. Chlorophyll fluorescence induction kinetics in wild type barley leaves and in leaves of a high fluorescing mutant viridis $-n^{34}$ are seen in Figure 3. Leaf segments ( 3 to $4 \mathrm{~cm}$ long) were taken 2 $\mathrm{cm}$ below the tips of the primary leaf of 7-dayald light-grown plants. The leaves were darkadapted for $20 \mathrm{~min}$ at $25^{\circ} \mathrm{C}$ in a moist chamber and subsequently illuminated. The leaves were photographed immediately and after $2,5,10,20$. and $40 \mathrm{sec}$ of illumination (Figure 4). The initial rapid rise in thorescence yield is seen in both wild type and viridis $-n^{34}$, the maximum intensity being attained within the first second of exposure (Figure 3). The wild type fuorescence then declines, a second peak of fluorescence occurs after about $4 \mathrm{sec}$, and the fluorescence declines again to eventually reach a steady state fuore-

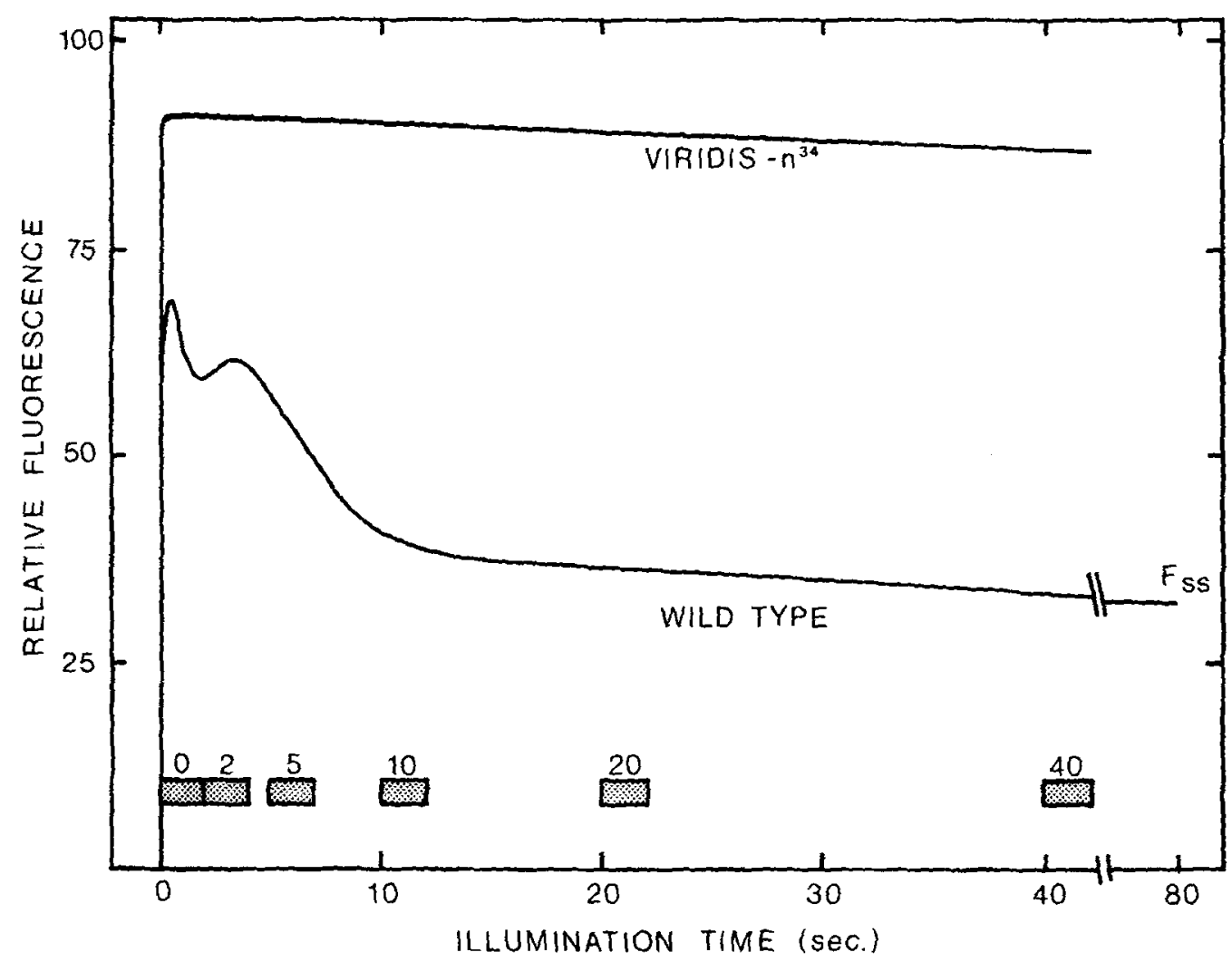

Figure 3. Kinetics of light induced chlorophyll fluorescence in leaf segments of Hordeum vulgare cv. Svalofs Bonus and the mutant viridis $-n^{34}$.

The kinetics were measured with a Plant Productivity Fluorimeter model SF-10 at $25^{\circ} \mathrm{C}$ and recorded on a strip chart recorder (REC 61, Radiometer, Copenhagen, Denmark). The leaves were irradiated with the same blue light used for photography (see section 2.4) and the built-in light source of the fluorimeter was not utilized. The rectangles at the bottom of the figure represent the times at which $2 \sec$ photographic exposures were made. 
scence level $\left(\mathrm{F}_{\mathrm{s}}\right)$. The transient rise in fluorescence is attributed to a substance $Q$ which quenches chlorophyll fluorescence in the oxidized state but not in the reduced state $(10,20)$. Q is in the oxidized state in dark-adapted leaves but is reduced by photosystem II during the first few seconds of irradiation, which causes chlorophyll fluorescence to rise during this period as the quenching effect is overcome. With continued irradiation this rise in fluorescence is followed by a slower decrease as $Q$ and other reductants produced by photosystem II are partially reoxidized as electron transfer reactions involving photosystem I exert an influence.

The mutant viridis $-n^{34}$ contains $75-80 \%$ of the amount of chlorophyll present in the wild type but is blocked at photosystem I (17). Consequently, the fluorescence rises to a higher level than in the wild type and this high level is maintained since re-oxidation of $Q$ in the light is

Figure 4. Photographic determination of light-induced chlorophyll kinetics described in Figure 3.

In each photograph the mutant viridis- $n^{34}\left(n^{34}\right)$ is on the left and the wild type (W.T.) is on the right. Irradiation time is indicated in the upper left hand corner of each frame. Exposure time was $2 \mathrm{sec}$.

Figure 5. Photographic detection of high fluorescing photosynthetic mutants of barley

The leaves were pre-illuminated with the blue light for one minute and then photographed using exposure times of 5, 2 and $1 \mathrm{sec}$. In each exposure the mutant viridis $-n^{34}\left(n^{34}\right)$ is on the left, the wild type (W.T.) in the centre, and viridis $-e^{64}\left(e^{64}\right)$ on the right.

Figure 6. A. Photograph of chlorophyll fluorescence from wild type (W.T.) (left) and the nuclear gene mutant viridis $-e^{64}\left(e^{64}\right)$ (right) leaf segments immersed in liquid nitrogen. Exposure time was $5 \mathrm{sec}$

B. Photograph of steady state fluorescence at room temperature of the maternally inherited mutant, Coast $V$ (right hand side) and the corresponding wild type, Coast CI-690 (W.T.) (left hand side). Exposure time was 5 sec.

Figure 8. Photographic measurement of the steady-state red fluorescence in dark-grown barley leaves illuminated with blue light.

The photographic system used is described under methods (2.4-2.6). A long wave pass LWP-590 nm emission filter was used for these photographs. From left to right: The first two leaves are of the barley mutant xantha- $\left.\right|^{8 I}$ blocked in the synthesis of protochlorophyllide; the two central leaves are the wild type; the two leaves on the right are barley mutant tigrina $-d^{\prime 2}$. In Figure $8 \mathrm{~A}$ the three leaf pairs were exposed for $0.25 \mathrm{sec}$. In Figure $8 \mathrm{~B}$ the exposure was increased to $2 \mathrm{sec}$, and in Figure $8 \mathrm{C}$ the exposure was $80 \mathrm{sec}$. The appearance of the leaves in white light is shown in Figure 8D

Figure 10. Photographic determination of the effect of heating on leaves of pea and papaya.

The experiment was carried out as described in Figure 9. Figure 10A, 10B, 10C and 10D are 1 sec exposures taken at temperatures corresponding to those designated A, B, C and D in Figure 9. The papaya ( $\mathrm{Pa}$ ) leaf segment is on the left and the pea segment (Pe) on the right. The BP-600-700 nm emission filter was used.

Figure 11. The effect of chilling at $0{ }^{\circ} \mathrm{C}$ on the chlorophyll fluorescence of pea (resistant to chilling injury) and peanut (susceptible to chilling injury).

Unchilled leaves were compared with leaves chilled at $0^{\circ} \mathrm{C}$ for 24 hours. The dark-adapted leaf discs were positioned on a copper plate embedded in ice to maintain their temperature near $0^{\circ} \mathrm{C}$ during photography, irradiated with blue light and then photographed. The leaves were irradiated for $15 \mathrm{sec}$ with blue light to allow maximal generation of $F_{v}$ before photographing. The figure shows $2 \mathrm{sec}$ and $1 \mathrm{sec}$ exposures of the film. In each exposure the pea discs are on the left $(\mathrm{Pe})$ and the peanut dises on the right $(\mathrm{Pn})$. Control (unchilled) dises are shown in the upper set of photographs $(\mathrm{CON})$ and chilled discs in the bottom set $(\mathrm{CH})$. The emission filter used in this series was the band pass BP-600-700 $\mathrm{nm}$.

Figure 12. The effect of chilling at $0^{\circ} \mathrm{C}$ on leaf discs of tomato $(\mathrm{T})$, potato $(\mathrm{P})$ and two somatic tomato/potato hybrids $7 \mathrm{c} / 13 / \mathrm{S} 25(7 \mathrm{c})$ and $2 \mathrm{a} / 2 \mathrm{a} / 36 \mathrm{~d} / \mathrm{S} 3(2 \mathrm{a})$.

The upper set of photographs shows unchilled (CON) leaves while the lower set shows leaves chilled for 24 hours $(\mathrm{CH})$. The leaves were chilled as described in Figure 11. The leaf discs were irradiated for 5 sec and then photographed using an exposure time of $4 \mathrm{sec}$, except for the potato leaf discs which were photographed using an $8 \mathrm{sec}$ exposure. This was necessitated by the lower fluorescence of the fresh potato leaves compared with the tomato and the hybrid leaves. 
4

\begin{tabular}{llllll}
\hline Osec & & 2 sec & & $5 s e c$ \\
$n^{34}$ & W.T. & $n^{34}$ & W.T. & $n^{34}$ & W.T.
\end{tabular}

$10 \mathrm{sec}$

$20 \mathrm{sec}$

$40 \mathrm{sec}$

$n^{34} \quad$ W.T. $n^{34}$ W.T. $n^{34} \quad$ W.T.

5
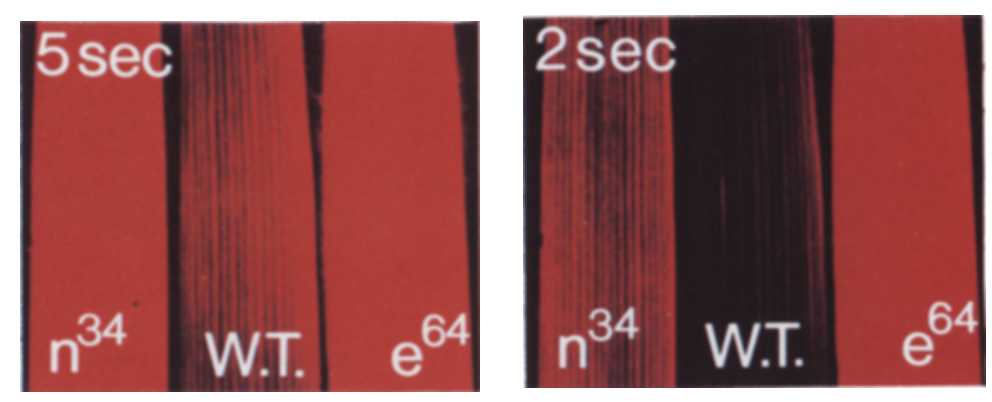

$1 \mathrm{sec}$

6

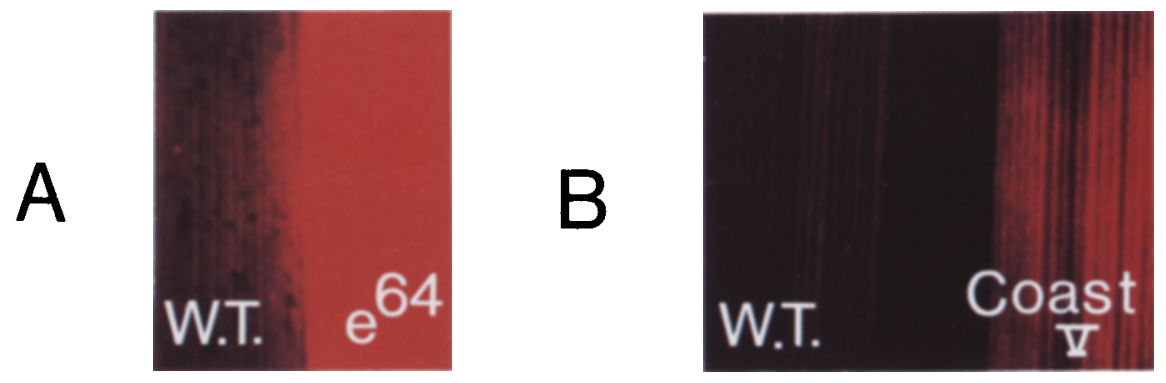

8
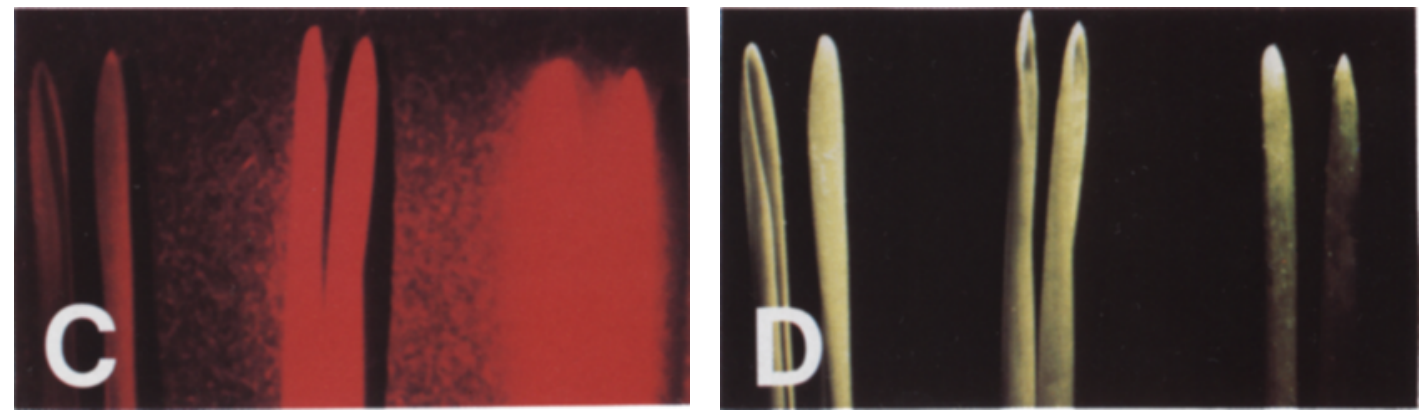
10

\section{A}

\section{B}

$\mathrm{Pa} \quad \mathrm{Pe}$

$\mathrm{Pa}$

$\mathrm{Pe}$

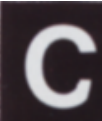

D

$\mathrm{Pa}$

$\mathrm{Pe}$

$\mathrm{Pa}$

$\mathrm{Pe}$

11

CON
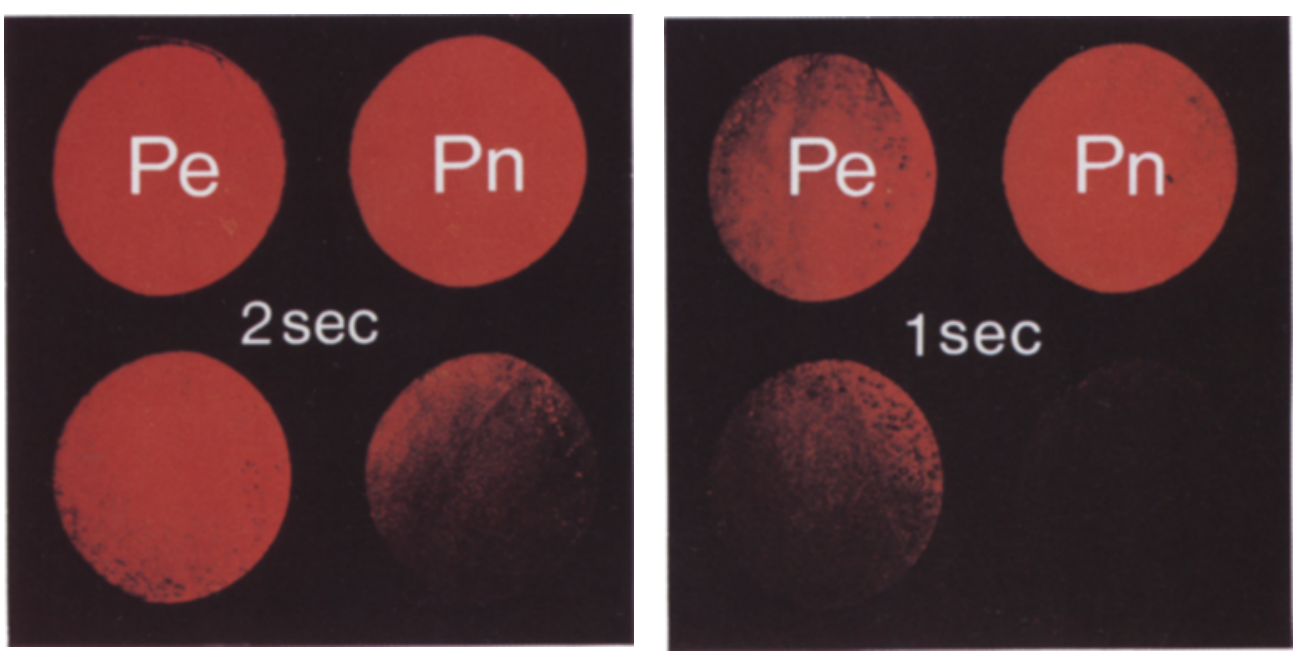

12

$\mathrm{CH}$
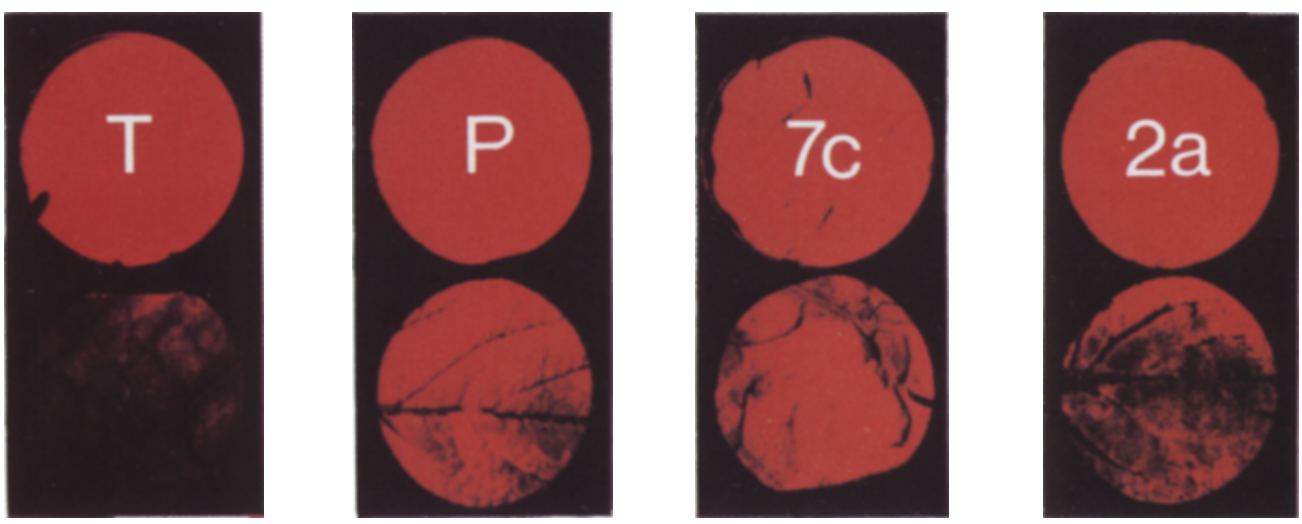
prevented by the block in electron flow at photosystem I.

The photographically recorded fluorescence of both wild type and mutant (Figure 4) corresponds well to the measured fluorescence (Figure 3). Although in the film sequence shown in Figure 4 the wild-type leaf segment is almost invisible after $40 \mathrm{sec}$ of irradiation, a longer exposure would allow recording of its steady state fluorescence.

\subsection{Photosynthetic nuclear gene mutants}

In using chlorophyll fluorescence photography to detect mutants of the same type as viridis $-n^{34}$, it can be seen from the consideration of chlorophyll induction kinetics (section 3.2) that the maximum difference between mutant and wild type phenotypes will be obtained if steady state fluorescence is photographed, that is, after about $1 \mathrm{~min}$ of irradiation. A series of time exposures may be required if the steady state fluorescence of the leaf materials being examined differs markedly in intensity. Figure 5 illustrates this. Leaves of wild type barley and two photosynthetic nuclear gene mutants, viridis $-n^{34}$ and viridis $-e^{64}$, were illuminated with blue light for one $\mathrm{min}$ and then photographed using different times for film exposure. The fluorescence of viridis- $e^{64}$ is clearly seen in a $1 \mathrm{sec}$ exposure, that of viridis $-n^{34}$ is just visible and the wild-type leaf fluorescence can hardly be seen at all. Using a $2 \mathrm{sec}$ exposure, the fluorescence of viridis $-n^{34}$ is now clearly evident, but the fluorescence of the wild type is seen faintly and a $5 \mathrm{sec}$ exposure is needed to bring up the fluorescence of the wild type. This series shows that the chlorophyll fluorescence at room temperature of the two mutants and wild type in this experiment recording fluorescence at wavelengths below $700 \mathrm{~nm}$ was in the order viridis$e^{64}>$ viridis $-n^{34}>$ wild type. While viridis $-n^{34}$ is defective in photosystem I activity (17), viridis $-e^{64}$ is low in both photosystems (30). The two mutants can be distinguished by studying the variable fluorescence, viridis $-e^{64}$ lacking variable fluorescence while viridis $-n^{34}$ has variable fluorescence due to a normally functioning photosystem II (26).

Chlorophyll fluorescence in leaves is greatly enhanced by cooling to $77 \mathrm{~K}$ in liquid nitrogen.
Figure 6A shows photographs of two leaf segments immersed in liquid nitrogen one of the wild type, the other of viridis $-e^{64}$. Although the total fluorescence yield of the wild type is increased at $77 \mathrm{~K}$, the distinction between viridis- $e^{64}$ and wild type seen in Figure 5 is maintained. The reason for this can be seen in Figure 7 which compares the fluorescence emission spectra of the wild type and viridis $-e^{64}$ at $77 \mathrm{~K}$ and at room temperature. At room temperature the most prominent peak is at 686 $\mathrm{nm}$ and this peak is much higher in viridis- $e^{64}$ than in wild type. At $77 \mathrm{~K}$ it is the $745 \mathrm{~nm}$ peak and not the $686 \mathrm{~nm}$ peak that is enhanced and while the increase in fluorescence yield at 745 $\mathrm{nm}$ is considerably greater in wild type than in viridis $-e^{64}$, the comparative insensitivity of the film used at this wavelength (Figure 2C) means that photographs of viridis- $e^{64}$ at $77 \mathrm{~K}$ still show a more intense fluorescence than photographs of the wild type.

\subsection{Maternally inherited mutant}

Chlorophyll fluorescence photography can also be employed in the detection and study of mutants showing maternal inheritance of a photosynthetic defect. Such mutants are most likely the result of a mutation in chloroplast DNA repetitions. Figure 6B compares one such mutant, Coast $V$, with the wild type from which it was derived. The mutant shows higher fluorescence than the wild type, indicative of a block in photosynthesis.

\subsection{Photography of chlorophyll precursors}

The photographic technique described for measuring chlorophyll fluorescence has also been used to detect different levels of chlorophyll precursors in dark-grown barley leaves (Figure 8). In this experiment the mutant tigrina- $d^{I 2}$, which has been found to accumulate high levels of protochlorophyllide in the dark $(5,18)$, and the yellow xantha- $\left.\right|^{81}$ mutant which while not forming protochlorophyllide, accumulated a low amount of magnesium protoporphyrin IX or its methyl ester in the dark, have been compared with the wild type. The mutant xantha- $l^{81}$ was obtained from the double mutant xantha- ${ }^{81}$ tigrina- $d^{12}$ isolated as described previously (8). 


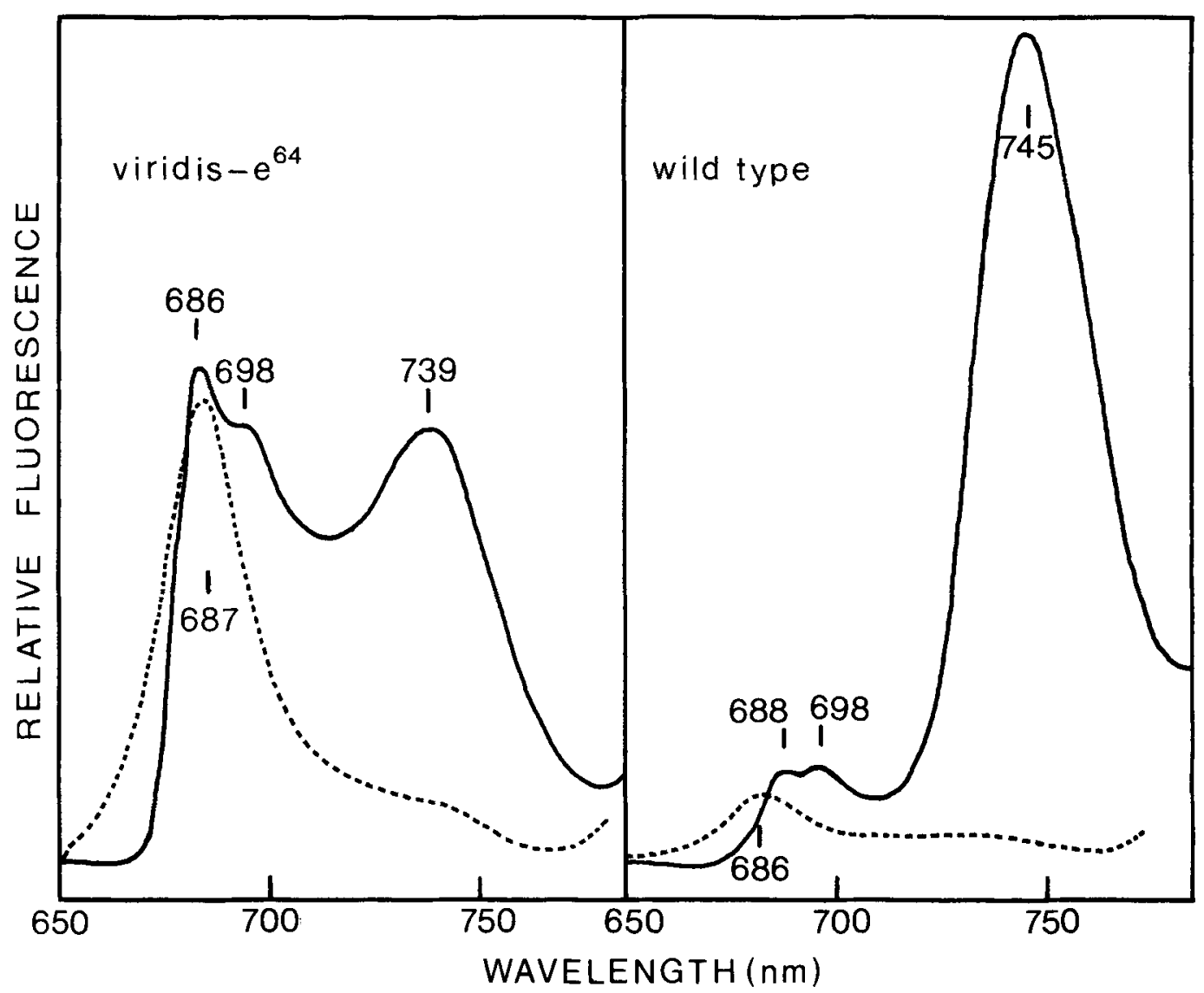

Figure 7. Fluorescence emission spectra of the primary leaf of viridis-e $e^{64}$ and wild type at $77 \mathrm{~K}(-)$ and at room temperature (-----).

The large difference in levels and kind of fluorescing porphyrins in these leaves can be estimated by comparison of the exposure time. While the tigrina-d ${ }^{12}$ mutant was correctly exposed at $0.25 \mathrm{sec}$, the wild type required 8 times as long (i.e. $2 \mathrm{sec}$ ) and the xantha- $1^{81}$ required 320 times the exposure of tigrina- $d^{I 2}$. The high level of protochlorophyllide in the leaves of tigrina- $d^{12}$ can be seen by the greenish tint of the leaves in white light while it is difficult to see any difference between the wild type and xantha-181 (Figure 8D).

\subsection{Heat injury}

Heating of leaves can effect changes in the photosynthetic system that result in altered kinetics of light-induced chlorophyll fluorescence
$(10,21,27)$. The variable fluorescence component, $F_{v}$, decreases as the electron transfer system becomes heat inactivated and there is an increase in $\mathrm{F}_{\mathrm{o}}$-fluorescence, the fluorescence rise taking place within the first nanosecond of illumination, as energy transfer from chlorophyll to the active centers is prevented. This increase in $\mathrm{F}_{0}$-fluorescence has been used to follow the onset of heat injury in plants and to rank plants for relative heat tolerance $(21,23$, 31). Thus the heat-induced change in $F_{0^{-}}$ fluorescence generally is seen to occur at lower temperatures in arctic and cool temperate species than in tropical species (31). This is illustrated (Figure 9) when leaves of pea, a temperate plant, and the tropical papaya are heated. The rise in $\mathrm{F}_{\mathrm{o}}$-fluorescence in the pea leaf occurs at temperatures 3 to $4{ }^{\circ} \mathrm{C}$ lower than in the papaya leaf. 
Heat damage can also be recorded photographically. Leaf segments of pea and papaya were placed side by side on a heating block and subjected to heating at a rate of $1^{\circ} \mathrm{C}$ per min, from $30^{\circ} \mathrm{C}$ to $55^{\circ} \mathrm{C}$. The leaves were photographed at one minute intervals during heating under continuous blue light. These conditions will record $F_{o}+F_{v}$, but by performing the photography while using continuous irradiation, i.e., at steady state fluorescence levels, the $F_{v}$ component will be small compared with $F_{0}$ and will be abolished because of heat inactivation above about $45^{\circ} \mathrm{C}$. The appearance of the two leaves at points corresponding to $\mathrm{A}, \mathrm{B}, \mathrm{C}$, and $\mathrm{D}$ in Figure 9 are shown in Figure 10. Initially there is only low fluorescence (Figure 10A). At point $B$ the pea leaf has increased its $F_{0}$ fluorescence (Figure 10B) which peaks at point $C$ (Figure 10C). The papaya leaf still exhibits low fluorescence. At point D the papaya leaf shows a definite increase in fluorescence while the fluorescence of the pea leaf has now begun to decrease (Figure 10D). In this experiment the exposure was chosen for the maximum fluorescence. If a longer exposure time had been used,

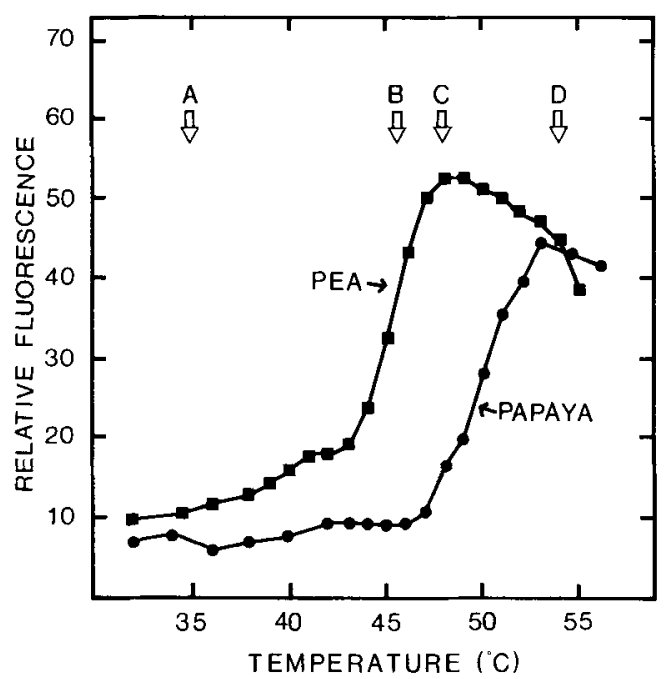

Figure 9. The effect of heating on the chlorophyll fluorescence of pea ( $\boldsymbol{\square})$ and papaya ( $)$ leaves.

Leaf segments were heated as described under methods (section 2.3). At each temperature the value of the initial fluorescence, $F_{0}$, was determined using a plant productivity fluorimeter as described for Figure 3. The temperatures denoted by arrows refer to Figure 10. the initial fluorescence would show red while the heat induced increase in $\mathrm{F}_{\mathrm{o}}$-fluorescence would result in photographic overexposure of the leaf segment.

\subsection{Chilling sensitivity}

Sensitive plants display an altered pattern of chlorophyll fluorescence when chilled (28). The $\mathrm{F}_{\mathrm{o}}$-fluorescence does not change, but as cellular chilling injury develops, there is a decrease in $F_{v}$ as well as in the rate of the $F_{v}$ rise due to the progressive inhibition of the water-splitting reaction of photosynthesis (28). To record this phenomenon photographically, leaves of peanut (chilling sensitive) and pea (chilling resistant) were first placed in ice for 24 hours. Discs of the chilled leaves together with sections of unchilled leaves were placed under glass on a copper block embedded in ice and photographed (Figure 11). By maintaining leaf temperature at $0^{\circ} \mathrm{C}$ during photography, the maximum fluorescence in control leaves can be more readily photographed (see sections 3.1 and 3.2) and this allows decreases in $F_{V}$ resulting from chilling to be more readily seen. Figure 11 shows that while chlorophyll fluorescence of the peanut leaf was drastically diminished following chilling, that of the pea leaf was only slightly affected.

The fluorescence changes seen by photography can be compared with measurements made of the changes in chlorophyll fluorescence induction kinetics in chilled leaves. The rate of rise in $F_{v}$ and the magnitude of $F_{v}$ (measured at $0^{\circ} \mathrm{C}$ ), decreases rapidly in peanut leaves kept at $0^{\circ} \mathrm{C}(28)$. After 1 day at $0^{\circ} \mathrm{C}, \mathrm{F}_{\mathrm{v}}$ is reduced to about $10 \%$ of the $\mathrm{F}_{\mathrm{v}}$ of the unchilled leaf and is not detected in leaves kept for 2 days at $0^{\circ} \mathrm{C}$. In contrast, the rate of rise of $F_{v}$ and the magnitude of $\mathrm{F}_{\mathrm{v}}$ are not reduced in pea leaves kept at $0^{\circ} \mathrm{C}$ for 2 days; in fact, there is little change in $F_{v}$ after 13 days at $0^{\circ} \mathrm{C}(28)$. These studies show that measurements of chlorophyll fluorescence and chlorophyll fluorescence photography can readily distinguish between species susceptible to cellular chilling injury and tolerant species.

The recent production of somatic hybrids of potato and tomato $(14,22)$ has provided interesting material for the study of chilling tolerance since one parent is chilling tolerant (potato) while the other (tomato) is chilling 
sensitive (29). Chlorophyll fluorescence photography has also been used to compare chilling tolerance of domestic tomatos with altitudinal forms of the wild tomato L. Hirsutum (R. PAULL and W. E. Rushton, pers. commun.). Figure 12 shows photographs of chlorophyll fluorescence in unchilled and chilled ( 1 day at $0^{\circ} \mathrm{C}$ ) leaves of tomato and potato and two tomato-potato somatic hybrids produced by fusion of tomato and potato protoplasts and regeneration of the hybrid plant from the fusion products. It can be seen that chilling greatly decreases chlorophyll fluorescence in tomato compared with the unchilled leaf while potato is only slightly affected by chilling. The hybrid 7c/13/S25 (58 chromosomes, potato chloroplast DNA) shows considerable chilling resistance while $2 a / 2 a / 36 d / S 3 ~(48-49$ chromosomes, tomato chloroplast DNA) is intermediate with regard to chilling injury (Figure 12). These observations are of interest since the hybrid $7 \mathrm{c} / 13 / \mathrm{S} 25$ may contain several potato chromosomes as well as potato chloroplast genes providing chilling resistance. On the other hand the hybrid $2 a / 2 a / 36 d /$ S3 is almost an amphiploid with one set of chromosomes from each species and the tomato chloroplast DNA. Screening methods based on photography of chlorophyll fluorescence could be useful in attempts to transfer chilling resistance genes from potato to tomato as suggested by SmiLLIE et al. (29).

\section{ACKNOWLEDGEMENTS}

We would like to thank Simon Gough and Gamini Kannangara for providing the protochlorophyllide mutants of barley and GuNILLA Høyer-Hansen, Birger Lindberg Møller, and DITER VON WETTSTEIN for the other mutant and hybrid plant material used in this study. Acknowledgement is also due to LISE TANG PETERSEN for printing the colour photographs and Ulla-KaRiN GibBons for preparing the figures.

\section{REFERENCES}

1. Bennoun, P., J. Girard \& N.-H. Chua: A uniparental mutant of Chlamydomonas reinhardtii deficient in the chlorophyll-protein complex CPI. Molec. gen. Genet. 153, 343-348 (1977)
2. Butler, W. L.: Chlorophyll fluorescence: A probe for electron transfer and energy transfer. In: Encyclopedia of Plant Physiology, New Series, Photosynthesis I. A. Trebst and M. Avron, eds., Springer-Verlag, Berlin, Vol. 5 pp. 149-167 (1977)

3. Elkin, L. \& R. B. PARK: Chlorophyll fluorescence of $\mathrm{C} 4$ plants. I. Detection with infra red color film. Planta 127, 243-250 (1975)

4. Elkin, L. \& R. B. PARK: Chlorophyll fluorescence of $\mathrm{C} 4$ plants. II. A photographic technique for obtaining relative fluorescence yields and spectra photographically. Planta 127, 187-199 (1975)

5. Gough, S. \& C. G. Kannangara; Biosynthesis of $\triangle$-aminolevulinate in greening barley leaves III: The formation of $\triangle$-aminolevulinate in tigrina mutants of barley. Carlsberg Res. Commun. 44, 403-416 (1979)

6. Graeb, G.: Fotolabor Handbuch. Wilhelm Knapp, Düsseldorf. 572 pp. (1970)

7. Hedgecoe, J.: The photographers Handbook. Doring Kindersley ed., Ebury Press, London. 352 pp. (1977)

8. Kahn, A., N. Avivi-Bleiser \& D. von WettSTEIN: Genetic regulation of chlorophyll synthesis analysed with double mutants in barley. In: The genetics and biogenesis of chloroplasts and mitochondria. T. Bücher, W. Neupert, W. Sebald, S. Werner eds., North Holland, Amsterdam. pp. 119-131 (1976)

9. Koshofer, G.: Agfachrome professional Filme, Aufnahmetechnik. Agfa-Gevaert AG Nr. 153, Leverkusen. 112 pp. (1974)

10. Lavorel, J. \& A.-L. Etienne: In vivo chlorophyll fluorescence. In: Primary Processes of Photosynthesis. J. Barber, ed., Elsevier/NorthHolland Biomedical Press, Amsterdam, pp. 203-268 (1971)

11. Lemoine, Y. \& H. Jupin: Analyse cinétique et spectroscopique de la fluorescence chez un mutant photosensible de Tabac. Photosynthetica 12, 35-50 (1978)

12. Melcarek, P. K. \& G. N. Brown: Effects of chill stress on prompt and delayed chlorophyll fluorescence from leaves. Plant Physiol. 60 , 822-825 (1977)

13. Melcarek, P. K. \& G. N. Brown: Chlorophyll fluorescence monitoring of freezing point exotherms in leaves. Cryobiol. 16, 69-73 (1979)

14. Melchers, G., M. D. Sacristan \& A. A. Hol.DER: Somatic hybrid plants of potato and tomato regenerated from fused protoplasts. Carlsberg Res. Commun. 43, 202-218 (1978)

15. Miles, D.: Genetic analysis of photosynthesis. 
Stadler Symp., University of Missouri, Columbia, Vol. 7 pp. 135-154 (1975)

16. Miles, C. D. \& D. J. Daniel: A rapid screening technique for photosynthetic mutants of higher plants. Plant Sci. Lett. I, 237-240 (1973)

17. Møller, B. L., R. M. Smillie \& G. HøyerHANSEN: A photosystem I mutant in barley (Hordeum vulgare L.) Carlsberg Res. Commun. 45, 87-99 (1980)

18. NieLSEN, O. F.: Macromolecular physiology of plastids. XII. Tigrina mutants in barley: genetic, spectroscopic and structural characterization. Hereditas 76, 269-304, (1974)

19. Öguist, G. \& N. O. Hellgren: The photosynthetic electron transport capacity of chloroplasts prepared from needles of unhardened and hardened seedlings of Pinus silvestris. Plant Sci. Lett. 7, 359-369 (1976)

20. Papageorgiou, G.: Chlorophyll fluorescence: An intrinsic probe of photosynthesis. In: Bioenergetics of Photosynthesis, Govindjee, ed., Academic Press, New York, pp. 319-371 (1975)

21. Pearcy, R. W., J. A. Berry \& D. C. Fork: Effects of growth temperature on the thermal stability of the photosynthetic apparatus of Atriplex lentiformis (Torr.) Wats. Plant Physiol. 59, 873-878 (1977)

22. Poulsen, C., D. Porath, M. D. Sacristan \& G. Melchers: Peptide mapping of the ribulose bisphosphate carboxylase small subunit from the somatic hybrid of tomato and potato. Carlsberg Res. Commun. 45, 249-267 (1980)

23. Santarius, K. A. \& M. Müller: Investigations of heat resistance of spinach leaves. Planta 146. 529-538 (1979)

24. Schreiber, U. \& W. Vidaver: Analysis of anaerobic fluorescence decay in Scenedesmus obliquus. Biochim. Biophys. Acta 387, 37-51 (1975)

25. Schreiber, U., W. Vidaver, V. C. Runeckles \& P. Rosen: Chlorophyll fluorescence assay for ozone injury in intact plants. Plant Physiol. 61 , 80-84 (1978)

26. Simpson, D. \& D. von Wettstein: Macromolecular physiology of plastids XIV. Viridis mutants in barley: Genetic. Fluoroscopic and ultrastructural characterization. Carlsberg Res. Commun. 45, 283-314 (1980)

27. Smillie, R. M.: Coloured components of chloroplast membranes as intrinsic membrane probes for monitoring the development of heat injury in intact tissue. Aust. J. Plant Physiol. 6. 121-133 (1979)

28. Smille, R. M.: The useful chloroplast: a new approach for investigating chilling stress in plants. In: Low Temperature Stress in Crop Plants. J. M. Lyons, D. Graham and J. K. Raison, eds., Academic Press, New York, pp. 187-202 (1979)

29. Smillie, R. M., G. Melchers \& D. voN WETTSTEIN: Chilling resistance of somatic hybrids of tomato and potato. Carlsberg Res. Commun. 44, 127-132 (1979)

30. Smillie, R. M., N. C. Nielsen, K. W. HenningSEN \& D. von Wetrstein: Development of photochemical activity in chloroplast membranes. I. Studies with mutants of barley grown under a single environment. Aust. J. Plant Physiol. 4, 145-438 (1977)

31. Smilue, R. M. \& R. Nott: Heat injury in leaves of alpine, temperate and tropical plants. Aust. J. Plant Physiol. 6, 135-141 (1979)

32. Wettstein, D. von, B. L. Møller, G. HøyerHANSEN \& D. J. Simpson: Genetic manipulation of photosystem I and photosystem II in chloroplast membranes. E. C. Solar Energy R \& D Programme. 3rd Co-ordination Meeting of Contractors, June 18-20, Brussels (1979)

33. Wiltens, J., U. Schreiber \& W. Vidaver: Chlorophyll fluorescence induction: an indicator of photosynthetic activity in marine algae undergoing desiccation. Can. J. Bot. 56, 27872794 (1978) 